\title{
The Second Wave of COVID-19 in Italy: What's Going On?
}

Umberto Cornelli, Giovanni Belcaro, Maria Rosaria Cesarone, Martino Recchia, and Roberto Cotellese

\section{ABSTRACT}

Background: a second wave (W2) of COVID-19 is affecting Italy.

Objective: to analyze the ratio between deaths and positive cases in two different 36-day periods of W2.

Methods: data were retrieved by the Official Bulletin of the Italian Protezione Civile. The analysis was based on mobile averages.

Results: The ratios deaths/positive cases in the first 35-day period form October 9th and November 13th were of $2.45 \pm 0.482$ and in the second 36day period from November 14th and December 19th was $2.37 \pm 0.416$. There is no statistical difference between the periods ( $p>0.05)$. The differences are significant $(p<0.01)$ in terms of trends, since in the first period the curve is flat, while in the second is growing.

Conclusions: the reason of the different trends are several, such as the starting of the colder season, the delay in providing with the common flu vaccination. the confusion about the initiative of lockdown, and the poor care for the older people.

Keywords: COVID-19; COVID-19 second wave; flu vaccination.
Published Online: January 14, 2021

ISSN: 2593-8339

DOI: $10.24018 /$ ejmed.2021.3.1.638

Umberto Cornelli *

Higher Technical Institute for Life

Technologies, Bergamo, Italy.

(e-mail: ucornelli@gmail.com)

Giovanni Belcaro

Darwin Lab \& Irvine Labs and the OOLEX C-Virus project, Spoltore (PE), Italy.

(e-mail: cardres@abol.it)

Maria Rosaria Cesarone

Darwin Lab \& Irvine Labs and the OOLEX C-Virus project, Spoltore (PE), Italy.

(e-mail: cmr.rosa@tiscali.it)

Martino Recchia

University of Lugano, Switzerland.

(e-mail: statmed ${ }^{\circledR}$ hotmail.com)

Roberto Cotellese

University G. d'Annunzio Pescara-Chieti, Italy.

(e-mail: r.cotellese@ unich.it)

*Corresponding Author

\section{INTRODUCTION}

During the first wave (W1) of COVID-19 in Italy, approximately between end of February and of June 2020, the official records [1] were reporting 240578 positive cases and 34788 deaths, corresponding to about $14.46 \%$ of mortality.

Starting from approximately September $25^{\text {th }}$, a second wave (W2) was appearing and updating the values to December $19^{\text {th }}$ the number of positive cases increased to about 1.63 million (1.634150) and deaths were 32708 accounting for $2.00 \%$ of mortality.

The deaths ratio during W2 was improving consistently compared to W1 when it was $14.9 \%$, thanks to the efficiency of the medical personnel (doctors, nurses, assistants) and also for the high number of asymptomatic swabs.

According to the official data [2], from the moment of positivity to the moment of deaths the median value was calculated in 12 days. However, the symptoms start as average 3 days after the infection which means that the ratio between positivity and deaths should be calculated with a shift of 15 days.
In relation to this, we are observing two different trends during the 72 days; in the first part of $\mathrm{W} 2$ between October $9^{\text {th }}$ and November $13^{\text {th }}$ (36 days) the ratio was flat, while in the following period between November $14^{\text {th }}$ and December $19^{\text {th }}$ (36 days) the ratio was increasing.

The aim of the present study is to consider the differences between these two periods during W2.

\section{MATERIAL AND METHODS}

The data of positive cases and deaths were taken from the Official Bulletins of the Protezione civile [1.]

\section{A. Statistical Methods}

The number of infected people and deaths can be influenced by the delays in regional notifications; therefore, they cannot be interpreted as a whole to describe the current epidemic evolution. To reduce these biases the Time Series Analysis was used to obtain simple moving averages of three values or SMA (3) that better describe the observed phenomena and make possible the calculation of a more realistic trends. The Regression Analysis also was used 
evaluate curve trends. The average and the relative SD of the two 36-day periods were calculated, and the $t$ test to measure the statistical difference.

The Software JMP14, SAS Institute was used for calculations.

\section{RESULTS}

The trend of the ratio deaths/cases during the $\mathrm{W} 2$ is reported in Fig. 1.

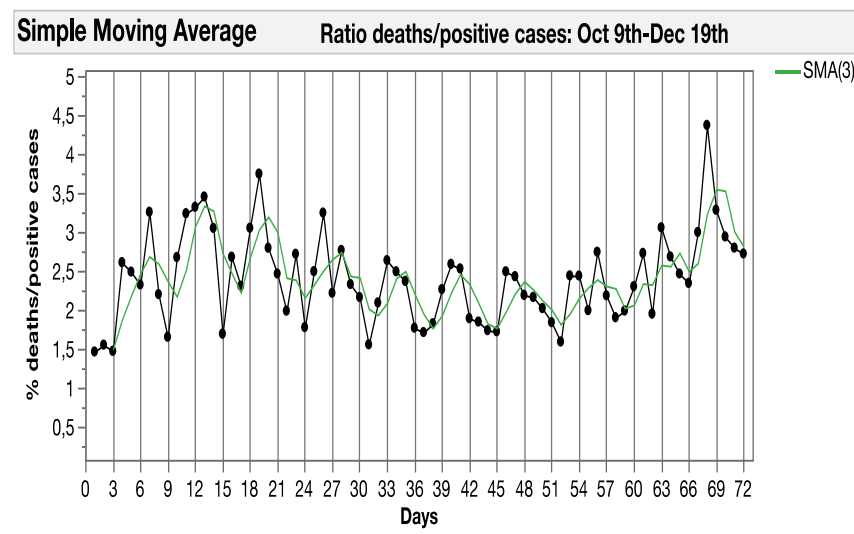

Fig. 1. Ratio deaths/positive cases during W2: SMA (3) Simple average Moving.

The curve was arbitrarily divided into two period of 36 days: the Ratio deaths/positive cases and the relative regression analysis of the first period are reported respectively in Fig. 2 and 3.

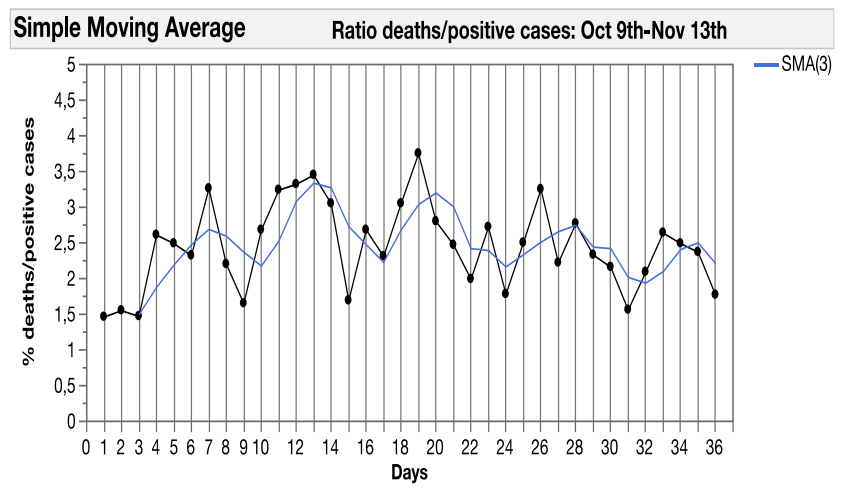

Fig. 2. Ratio deaths/positive cases in the period of October $9^{\text {th }}$ and November $13^{\text {th }}$.

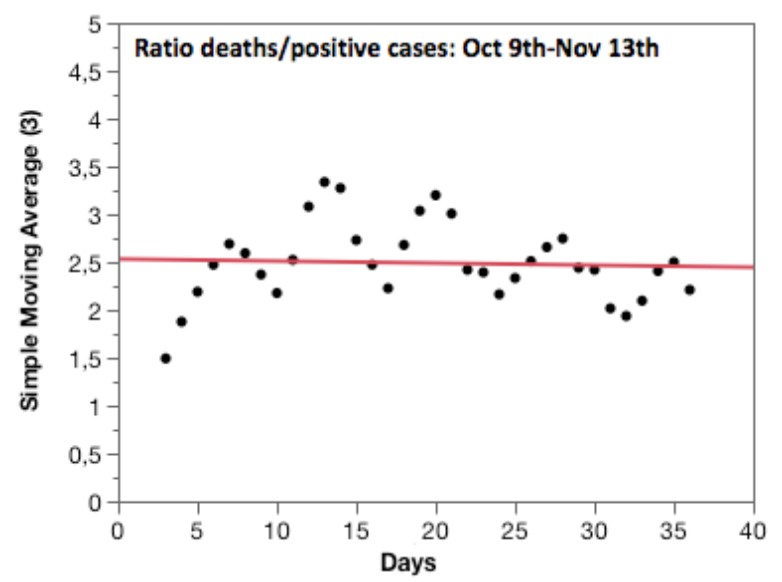

Fig. 3. Regression analysis of the Ratio cases/deaths in the period of October $9^{\text {th }}$ and November $13^{\text {th }}$.
The Ratio deaths/positive case and the relative regression analysis of the second 36-day period are reported respectively in Fig. 4 and 5.

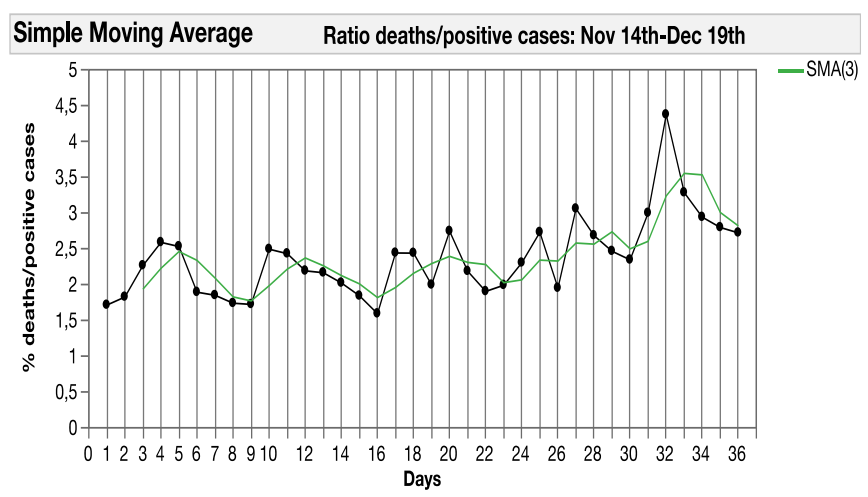

Fig. 4. Ratio deaths/positive cases in the period of and November $14^{\text {th }}$ and December $19^{\text {th. }}$

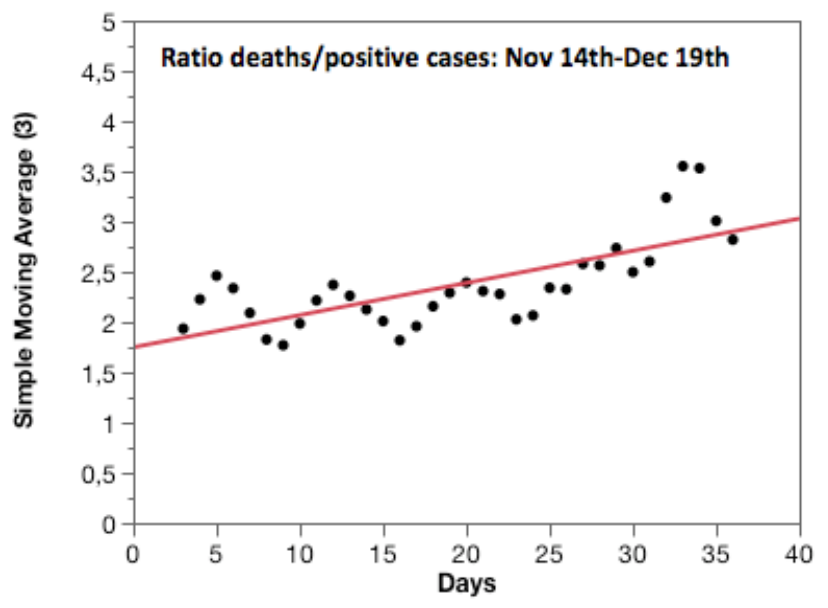

Fig. 5. Regression analysis of the Ratio cases/deaths in the period of November $14^{\text {th }}$ and December $19^{\text {th }}$.

The trends of the curves of the two 36-day periods are different ( $t$ test $\mathrm{p}<0,05)$, despite the average rates are similar corresponding respectively to $2.45 \pm 0.482$ and $2.37 \pm 0.416$ (t test $\mathrm{p}>0.05)$.

\section{DISCUSSION}

The present study has some limitations due to the median time calculated between the viral infection and death which has been settled at 15 days.

This was based on the consideration that as average the symptoms appear 3 days after the infection, and the median time from symptoms to death was reported to be 12 days [2].

In case a shorter period had been chosen ( $<15$ days), the differences would be more evident. The opposite can happen in case of a longer period of time will be considered (> 15 days).

However, most of the deaths were recorded at home, and in these cases the period between symptoms appearance and death is much shorter due the lack of appropriate medical assistance. Approximately $>80 \%$ of the cases was dying out of the hospital, which means that the trend differences between the two 36-day periods will be underestimated. 


\section{A. The Two Waves}

One of the frequent aspects of pandemias is the presence of waves. This has been described for the Spanish flu, characterized by 3 waves, and also during the Hong Kong flu consistent with 2 waves [3].

Each country may have different figures or trends due to several reasons, and the present study was focusing the situation in Italy, considering 72 days of the second wave (W2) in terms of ratio between deaths and positive cases.

When comparing the trends of the first and the last 36-day periods a significant differences were found.

\section{B. The Possible Reason of the W2}

It is known that during the summer, corresponding to the end of the first phase of COVID-19 (W1), the people were free to move through Italy, and one may suppose that plenty of asymptomatic subjects were moving around acting as triggers for the W2.

In Italy, the period of summer holidays, a part for workers in the area of tourism, for all the other activities (e.g., schools, Industries, small businesses) starts approximately in the last half of June and finishes about the first half of September.

By the end of September, usually the vacation is almost concluded, and the activities restart again with the common intensity. W2 initiates around the end of September and was much more severe than W1, particularly in the second 36-day period.

\section{The Trend Difference between the First and the Second Part of $W 2$}

The first cause can be the winter season, which is closer to the last 36-day period. The cold may have given the virus a more appropriate ground to concentrate and aggress the people, or the people was more sensible to the COVID-19.

One may not exclude that the increase of air pollution in terms of PM2.5 and $\mathrm{NO}_{2}$ could be crucial facilitate the viral aggression [4] Furthermore, with the colder season people tend to aggregate in crowded places (e.g. shopping centers, bars, restaurants).

The second cause could be the starting of the common flu, which may be responsible for a double infection, addressed particularly to elderly people who do not have a sufficient immune defense capacity. This is consistent with the median age of deaths which was reported to be $80-81$ years [2].

The vaccination of elderly people for the common flu was delayed in many Regions for logistic reason, and it is known, at least in Italy, that vaccination reduces significantly the deaths due to COVID-19 [5].

A third cause could be a possible viral mutation, as it seems to happen in the Southern part of UK, in Netherlands, Denmark, and Australia, Africa, but in Italy there are no documents to support this hypothesis.

The shortage of ICUs (Intensive care Units) can be ruled out, because in the Italian Regions considered the most equipped for these structures, the deaths ratio was even higher than in the other Regions. Furthermore, the highest number of deaths were recorded at home or in nursing homes, in other terms out of the hospitals.

A fourth cause can belong to the confusing information given to the people in terms of prevention, since each Region was deciding about the anti COVID-19 initiatives in terms of lockdown. It was also happening that each Province was acting independently, and one may expect that because of this people was taking their own initiatives.

Despite the viral infection is spread through the mouth, any suggestion was done by virologists, immunologists, epidemiologists, or by the media (TV, magazines,) that the oral hygiene $[6,7]$ is the first barrier against the viral spreading making much more efficient the mask protection.

One may not forget that the transmission of the virus is not happening only in restaurants, supermarkets, public transportations, but also during working time when people is wearing the mask, therefore oral hygiene represents an important tool for the prevention. The extremely high frequency of viral infection in the most industrialized area in Italy (e.g., Lombardia, Veneto, Piemonte) means that working place should be addressed with more care using all the possible tools against COVID-19 [8].

Among the many other reasons than can be evoked, one may not forget the rumors through Italy, such that sick old people were almost abandoned, either at home or in the nursing homes.

This disease for sure has a tremendous impact on the Country economy, and unfortunately some politicians and top managers were publically declaring one may expect our grandfather will dye, or even worse that we have to choose between starving or to dying of disease, and of course this is not appropriate.

\section{CONCLUSIONS}

The reason of the different trends between the ratio's deaths/positive cases between the two 36-day periods of W2 are several. It can be due to the starting of the colder season and to the delay in providing with the common flu vaccination. The poor care for older people is probably one of the most important causes, and the confusion generated by the cumbersome initiatives in terms of lockdown was also another reason.

At the end, each one for itself and God for all.

\section{ACKNOWLEDGEMENTS}

We need to give our condolences to the families of COVID-19 victims, and our proximity to the people suffering from this viral infection.

UC conceived the trial; UC, GB, MRC, RC were collecting the data; MR was in charge to make the statistical evaluation, UC wrote the text.

\section{ETHICAL STATEMENT}

The manuscript is original, has not been published before and is not being considered for publication elsewhere. All the authors mentioned in the manuscript have agreed on the authorship, read, and approved the manuscript, and given consent for submission and subsequent publication for the manuscript. 


\section{REFERENCES}

[1] Coronavirus in Italia, tutti I bollettini della protezione CivileCorriere.it. https//www.corriere.it/salute/malattie_infettive/20 _marzo_27/cornavirus-italia-protezione civile.

[2] Palmieri L, Agazio E, Barbariol P, Bella A, Bellino S et al. Surveillance Group ISS. Characteristics of deceased patients positive to SARS-Cov. 2 in Italy: Available Data at November $25^{\text {th }}, 2020$.

[3] Akin L, Gözel MG. Understanding dynamics of pandemics. Turkish J Med Sci.,vol. 50, pp. 525-519, 2020.

[4] Fiasca F, Minelli M, Maio D, Minelli M, Vergallo I et al. Association between COVOD-19 Incidence rates and exposure to PM2.5 and $\mathrm{NO}_{2}$ : a nationwide observational Study in Italy. Environ Res Public Health, vol.17 DOI:10.3390/ijrph17249318, 2020.

[5] Cornelli U, Belcaro G, Cesarone MR, Recchia M, Cotellese R. The COVID-19 History in Italy: Correlations with Environmental, Demographic Variables and Chronic Diseases Therapy. J Med Clin Res Rew., vol. 4, no 10, pp. 1-13, 2020.

[6] Mayers C, Robinson R, Milici J et al. Lowering the transmission and spread of human coronavirus J Med Virol., 1-8 DOI: 10.1002/jmv.26514.,pp 1-8, 2020.

[7] Belcaro G, Cornelli U, Cesarone MR, Feregalli B, Cotellese R et al. Decrease in covid-19 contagiouness: virucidals control the presence of covid in saliva and salivary glands. Med Clin Res., vol.5, no 4, pp 1-5, 2020.

[8] Cornelli U, Belcaro G, Cesarone MR, Cotellese R. Coronavirus Cov19: The status in Italy taken as an example of the virus spreading in the world. J Med Clin Res Rew., vol. 4, no 5, pp. 1-9, 2020. 